\title{
Comparing Local and International Chinese Students' English Language Learning Strategies
}

\author{
Margreat Aloysious Anthony and Sree Nithya Ganesen \\ (HELP University College, Malaysia) \\ doi:10.7575/aiac.alls.v.3n.2p.52
}

\begin{abstract}
According to Horwitz (1987), learners' beliefs about language learning are influenced by previous language learning experiences as well as cultural background. This study examined the English Language Learning Strategies between local and international Chinese students students who share the same cultural background but have been exposed to different learning experiences. Given the significant number of local and international Chinese students enrolled in educational institutions, there is a need to understand the differences and similarities in the learning strategies of these two groups. The sample for the study comprised of 60 local and 50 international Chinese students currently enrolled at a local private college. The Oxford Strategy Inventory for Language Learning (SILL) was administered as a measure of learning strategy preferences. The study reveals that language learning experiences as well as socioeconomic status impact the learning strategy adopted by both local and international Chinese students. The findings of this study point to the need to address the needs of these students in order to enhance their English language learning experience in Malaysia.
\end{abstract}

\section{Introduction}

Cultivating students' attitudes, habits and competence as a lifelong learner has become the major goals of higher education. Knowles (1975) stated that teachers have to help learners develop the attitude and concept that learning is a lifetime process, and learners need to be equipped with the skills of self-directed lifelong learning. In order to achieve the skills of self-directed lifelong learning, one has to be equipped with the language learning strategy as it is part of lifelong learning. In order to further understand the language learning strategy, Oxford (1990) had referred it to the specific actions, behaviors, steps or techniques that students use to improve their progress in apprehending, internalizing and using the second language. 
Bremmer (1999) and Oxford (1989) reported that second language proficiency/achievement is related to language learning strategies. Meanwhile, Chamot and Kupper (1989) reported that all language learners use types of language learning strategies to a certain level, but there are differences in the frequency and choice of use among different learners. Also, Oxford; (1990) reported that it appears that successful language learners have the ability to orchestrate and combine particular types of language learning strategies in effective ways according to their own learning needs. Therefore, the research aims to look into learners' language learning strategies in order to help the instructors to better understand the learner strategies used and to promote learner autonomy.

Based on the belief that research is not a process of providing something, but rather a process of discovering and learning (Sherman \& Webb, 1988; Erickson, 1990), the aim of the research is to address the following questions:

1. Is there a significant difference in the learning strategy between the local and international Chinese students?

2. Does socioeconomic status impact the learning adopted by local and international Chinese students?

3. Does the language learning experience impact the learning adopted by local and international Chinese students?

\section{Literature review}

Language learning strategies are any set of actions, plans, tactics, thoughts or behaviors that the learners employ to facilitate the comprehension, storage, retrieval, and use of information (Rubin, 1987; O’Malley and Chamot, 1990). Therefore employing strategies of any kind is goal-oriented. According to Tarone (1983), this goal is realized by developing linguistic and sociolinguistic competence in the target language. To achieve this end, as Nibset and Shucksmith (1986) state, successful language learners develop a range of strategies from which they are able to select appropriately and adapt flexibly to meet the needs of a specific context.

Although difficulties remain even at the basic level of terminology, awareness has been slowly growing of the importance of the strategies used by learners in the language learning process. Teachers use the same teaching methodology for all students in a class. But it is up to the students' whether to make it as an input or not. At times, students may just listen to what 
the teacher says and not learn from it. Actually, students need to work on their learning strategies in order to make their learning effective. By recognising that "learning begins with the learner", Nyikos and Oxford (1993, p.11) acknowledge the basic reality that, like the proverbial horse led to water but which must do the drinking itself, even with the best teachers and methods, students are the only ones who can actually do the learning. This growing awareness has resulted in more recent years in what Skehan $(1989$, p.285) calls an "explosion of activity" in the field of language learning strategy research.

One of the earliest researchers in this field, Rubin (1975, p.43) provided a very broad definition of learning strategies as "the techniques or devices which a learner may use to acquire knowledge". In 1981, she identified two kinds of learning strategies: those which contribute directly to learning, and those which contribute indirectly to learning. The direct learning strategies she divided into six types (clarification/verification, monitoring, memorization, guessing/inductive inferencing, deductive reasoning and practice), and the indirect learning strategies she divided into two types (creating opportunities for practice and production tricks).

From a strategic point of view, individual learners are seen as capable of making deliberate efforts to use learning strategies in order to promote their own learning (Rubin, 1987). Gardner and MacIntyre (1993) proposed a model of language learning whereby language learning strategies interact in a complicated way with other individual factors such as intelligence, aptitude, attitudes, motivation and anxiety. Other possible learner variables which have the potential to affect the choice of language learning strategies might include personality, learning style, beliefs and personal circumstances. The other factors which are often thought to have a strong influence on the way individual learners go about their learning, and which will be examined further in the course of the present study, are the socioeconomic status and the language learning experiences of the students.

\section{Methodology}

This study took place in a private institution. The sample was chosen using a purposive sampling with a focus on the Chinese students. This is because the Chinese students are among the students with the highest enrolment both as international students in Malaysia as well as highest enrolment in private institutions (www.mohe.gov.my). Among the Chinese students, there are the locals and the international Chinese students. Locals are the Malaysian 
Chinese students and international being the Chinese students from China. The reason behind studying two groups is because both the local and international Chinese students share the same cultural background but are exposed to different learning experiences. Due to the different learning experiences, it is believed that these two groups would have different language learning strategies and different learning attitudes.

Two sections of questionnaire were used. First being the Strategy Inventory for Language Learning (SILL, Version 7.0, Oxford, 1990) was used to determine language learning strategies between the local and international students. SILL consists of 50 close-ended questions with a five-point Likert scale ranging from 1 to 5. SILL includes direct and indirect strategy categories. The direct categories entail memory strategies, cognitive strategies and compensation strategies. These strategies are directly applied to learning or use the language through the process of storing, retrieving and manipulating. Cognitive and memory strategies include ways to deal with information to enhance learning; compensation strategies help learners find ways to make up for inadequacies in their knowledge when they use the language. On the other hand, indirect strategies entail meta-cognitive strategies, affective strategies and social strategies. They do not involve the target language directly, but are also crucial in the language learning process because they facilitate the language learning and as a result, can enhance the learning. Meta-cognitive strategies refer to executive skills regarding planning, monitoring and evaluating learning; social/affective strategies involve skills in interacting with others and looking after one's own affective state. The items are divided into six parts, covering six different language learning strategies:

a. memory (remembering more effectively)

b. cognitive (using all one's mental processes)

c. compensation (compensating for missing knowledge)

d. meta-cognitive (organizing and evaluating one's learning)

e. affective (managing one's emotions)

f. social (learning with others)

Second, the background information section was used to determine the socioeconomic and learning experiences of the students. The background information section was designed as to obtain answers for research questions two and three. 
A quantitative approach was used in this research. The quantitative approach was done by analysing the participants' answers to the questionnaire and transforming it into statistical data. The research began by identifying the samples, followed by students answering the questionnaire, analyzing the data by using the Statistical Package for the Social Sciences (SPSS) and finally the findings.

\section{Findings}

The data were analyzed using the SPSS. The analysis is presented with the three research questions as its basis. The data were collected from the SILL and background information questionnaire. For the first research question 'Is there a significant difference in the learning strategy between the local and international Chinese students?' Table 1 gives a summarized version of the analysis from the SPSS.

Table 1: Mean difference in the language learning strategies between the local and international students

\begin{tabular}{cccc}
\hline Learning strategies & Local (Malaysia) & International (China) & Difference (Mean) \\
\hline $\begin{array}{c}\text { Part A: Memory } \\
\text { strategies }\end{array}$ & 3.10 & 4.97 & 1.87 \\
$\begin{array}{c}\text { Part B: Cognitive } \\
\text { strategies }\end{array}$ & 3.46 & 3.61 & 0.15 \\
$\begin{array}{c}\text { Part C: Compensation } \\
\text { strategies }\end{array}$ & 3.66 & 3.56 & 0.10 \\
$\begin{array}{c}\text { Part D: Metacognitive } \\
\quad \text { strategies }\end{array}$ & 3.42 & 3.82 & 0.34 \\
$\begin{array}{c}\text { Part E: Affective } \\
\text { strategies }\end{array}$ & 3.10 & 3.35 & 0.34 \\
Part F: Social learning & 3.03 & 2.98 & 0.05 \\
$\quad$ strategies & & & \\
\hline
\end{tabular}

Table 1 shows that there is a difference in Part B to Part F but there is only significant difference in Part A where the memory strategy is a difference in mean which is more than 1.00. This supports what Politzer (1983) says that Asian students preferred strategies, such as memorization. In this research, results show that both the local and international students generally use all the strategies from medium to high frequency (High-3.5-5.0, Medium-2.53.4, and Low-1.0-2.4). The frequency used for memory strategy also falls in the medium to high category which supports Politzer (1983). Yet, this research shows that though both the local and international students preferred memory strategy, the international students use the memory strategy more frequently than the local students. 
Besides that, there is also a low frequency difference for Part $\mathrm{F}$ which is social learning strategy. Generally, students had used this strategy in the lowest frequency (2.98 \& 3.03) with a mean difference of 0.05 which is below 0.10. This supports what Politzer \& McGroaty (1985) says that Asian students were less likely to engage in certain communication-type strategies than other students. This further explains that though Chinese students use the learning strategies from medium to high frequency, they use the social learning strategy less frequently compared to the other strategies. However, when compared between these two groups, the local students had used the social learning strategy more frequently than the international students. This supports Wharton (2000) who stated that language learning strategy use of university students in Singapore indicated a high mean and ranking of social strategy use. In this research, the case of Malaysian students is the same as the Singaporean students who used the social strategy more frequently.

For research question two 'Does socioeconomic status impact the learning adopted by local and international Chinese students?' The socioeconomic status of a student is defined by their parents' occupation. The result shows that there were more professional parents in both groups. Most of the local and international students' parents are professionals with local students having 63\% professional parents and 37\% non-professionals and international students having 79\% professional parents and 21\% non-professional parents. It can be assumked that having professional parents can provide students with a better socioeconomic status that, in turn, can impact the learning adopted by local and international Chinese students. This in a way encourages the students both local and international to use the language learning strategies more frequently.

For research question three 'Does the language learning experience impact the learning adopted by local and international Chinese students?' areas like students weekly study hours spent in school, languages spoken at home and their interest in English language were focused on. Figures 1 to 6 show the areas mentioned above and further answer research question 3. 


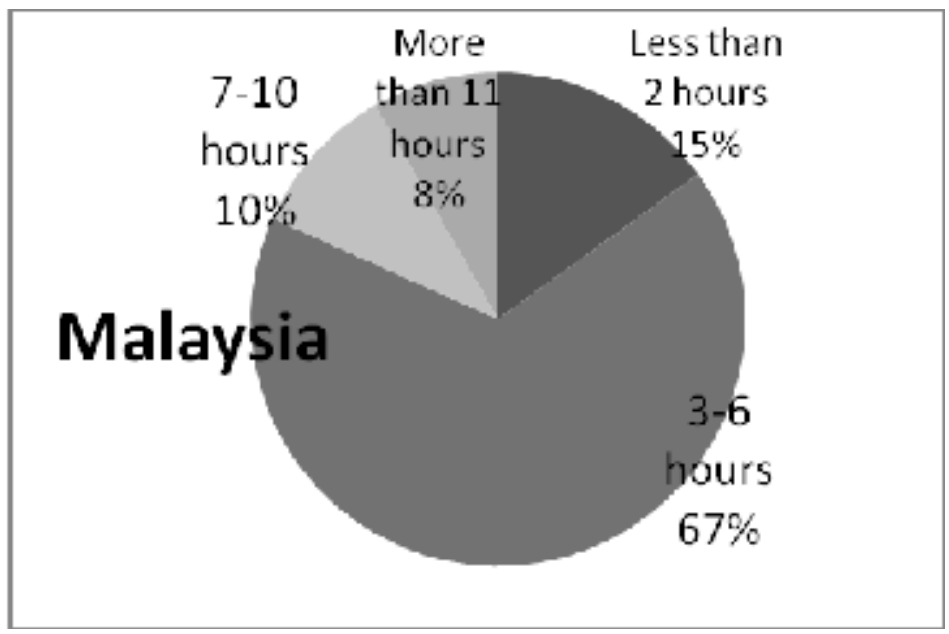

Figure 1: Hours spent studying English per week in school by the local students

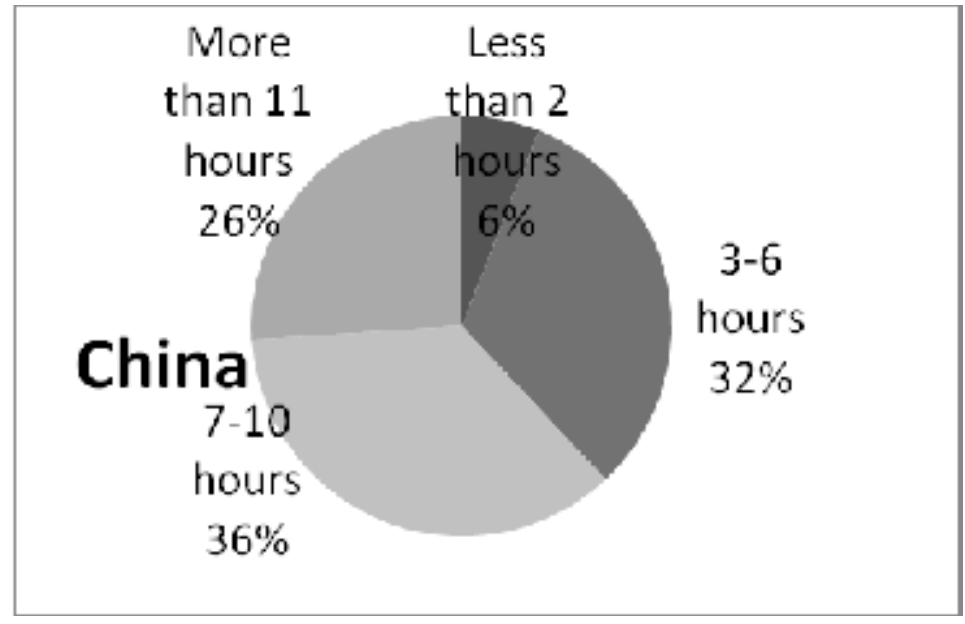

Figure 2: Hours spent studying English per week in school by the international students

Figures 1 and 2 show the hours spent studying English in school by both the local and international students. Each category of hours indicates time spent in a week by the students. Figure 1 explains about the hours spent by the local students which show that most of the students spent about 3 to 6 hours per week in school studying English. Meanwhile in Figure 2, most of the international students had spent about 7 to 10 hours per week in school for studying English. Though the percentage of the international students is less than the local students, the international students had used the other two categories; 3 to 6 hours and more than 11 hours, more frequently then the local students. Generally, it explains that the international students had used more hours per week in school for studying English. 


\section{Chinese Malaysia \\ $13.3 \%$}

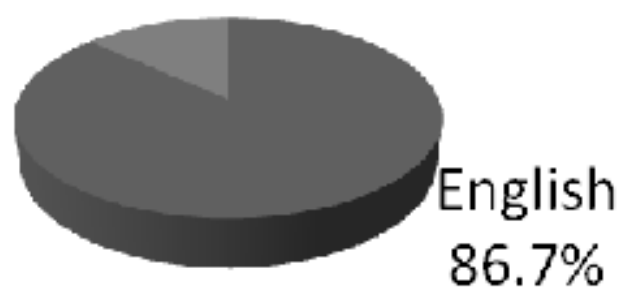

Figure 3: Languages spoken at home by the local students

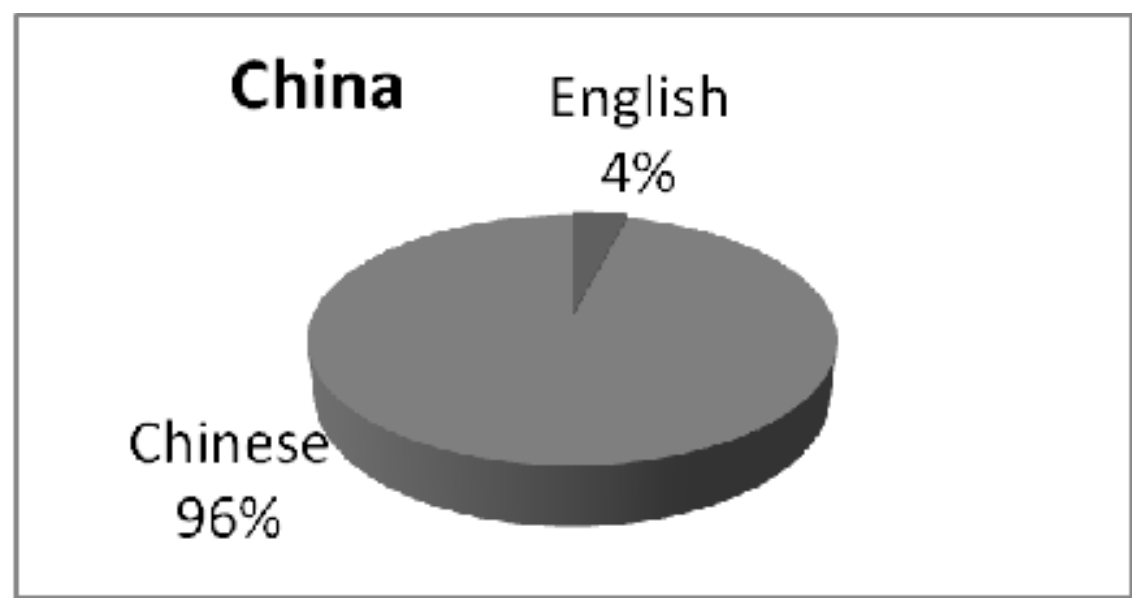

Figure 4: Languages spoken at home by the international students

Figures 3 and 4 show the languages students speak at home. All students poke either English or Chinese languages. Figure 3 shows that $86.7 \%$ of local students speak English at home and only about $13.3 \%$ of them speak Chinese at home. This means that most of the local students speak English at home. Meanwhile, Figure 4 shows that $96 \%$ of the international students speak Chinese at home and only 4\% of them speak English at home. This means that most of the international students speak Chinese at home. 


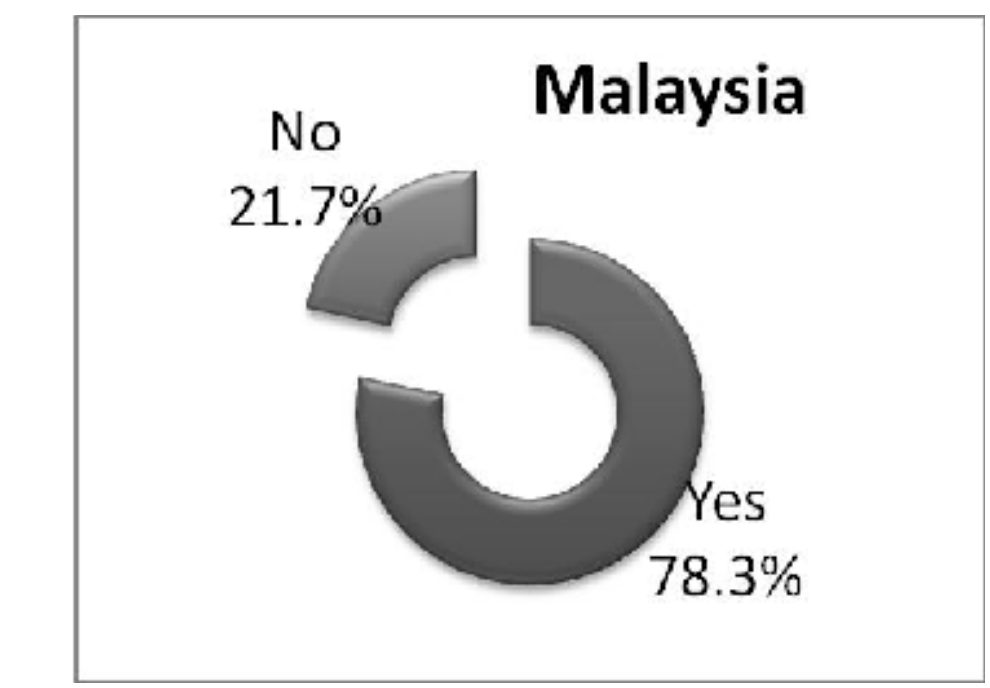

Figure 5: Local students' interest in the English language

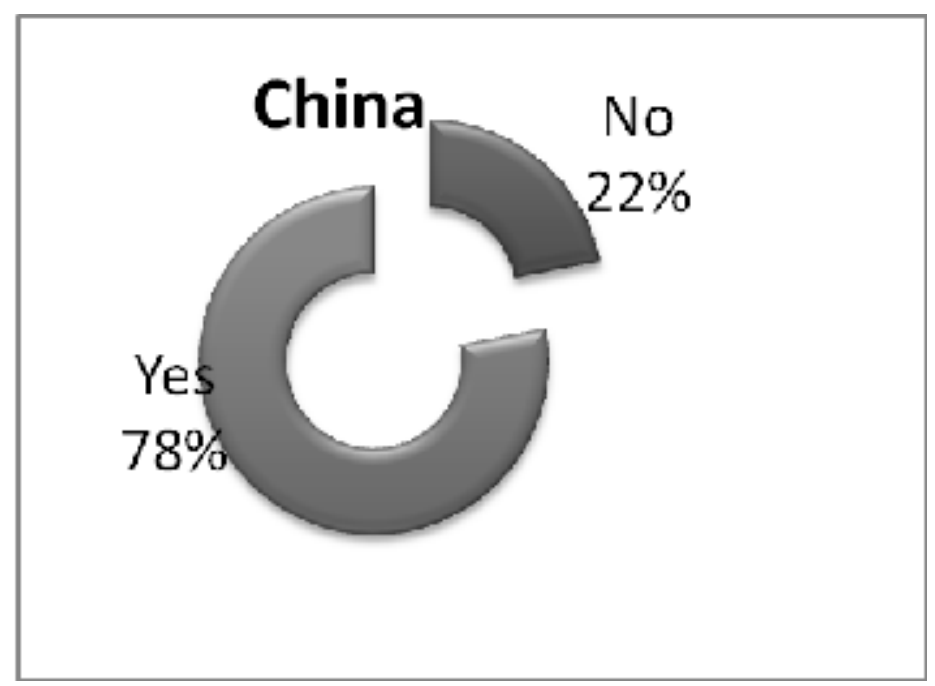

Figure 6: International students' interest in the English language

Figures 5 and 6 show the students' interest in the English language. Most of the students, both local and international answered that they were interested in the English language. The local students answered 'Yes' to having interest in English with a percentage of $78.3 \%$ and international students with $78 \%$ to 'Yes'. This means that most of the students, both local and international students were interested in the English language.

Generally, the international students used the language learning strategies more frequently than the local students in the memory strategy, cognitive strategy, meta-cognitive strategy and affective strategy. This could be due to the hours spent by the international students in school for a week is higher in percentage than the local students. However, the local students' frequency in the learning strategy also does not have much difference in mean except for the 
memory strategy. Moreover, the local students had a higher frequency in both the compensation strategy and social strategy. This could be due to the local students using the English language at home and this shows their interest in the language. This further explains that spending more time for studying English in school alone does not help a student to improve in all the six strategies but practicing the language at home, would actually encourage the students to improve in the communication as what the local students had achieved in the compensation and social strategies.

\section{Discussion}

The findings show that both the international and local students use the strategies from medium to high frequency (lowest=2.98 \& highest=4.97) which explains that they are moderate to high users of the language learning strategy. However, the international students used the memory strategy with a significantly higher difference than the local students. Meanwhile, though the social learning strategy was among the less frequently used strategy, the local students used the social learning strategy higher than the international students. It is also against some findings which say that Asian students were less likely to engage in certain communication-type strategies than other students (Politzer \& McGroaty, 1985).

\section{Conclusion}

It is clear that every student has a different learning strategy. Language instructors should understand students' language learning strategy to cater to the different needs of students who have different learning experiences. This will help the instructors and institutes to offer the most appropriate courses to suit the students' needs and level, and eventually achieve the best teaching and learning results. They should also offer various opportunities for students to utilize strategies in their language learning. Instructors should not only focus on the strategies that students originally employ, but also raise the students' awareness of other strategies they use less frequently or not at all.

By doing so, the students will adopt other strategies which they do not use or use less frequently and form a friendly studying environment with other students from different nationalities. In other words, the international students would also get a chance to adapt to the Malaysian way of teaching and learning. 


\section{References}

Bremmer, S. (1999). Language learning strategies and language proficiency: Investigating the relationship in Hong Kong. Canadian Modern Language Review, 55 (4): 490-514.

Chamot, A.U., \& Kupper. L. (1989). Learning strategies in foreign language instruction. Foreign Language Annals, 22, 13-24.

Gardner, R. \& P. MacIntyre. (1993). A student's contributions to second-language learning.Part II: Affective variables. Language Teaching 26:1-11. Cambridge: CUP.

Horwitz, E.K. (1987). Surveying student beliefs about language teaming. In A.L. Wenden \& J. Robin (Eds.), Learner strategies in language learning (pp. 119-132). London: Prentice Hall.

Knowles, M. S. (1975). Self-directed learning. New York: Association Press.

Nibset, J., and Shucksmith, J. (1986). Learning strategies. Boston: Routledge and Kegan Paul.

Nyikos, M., \& Oxford, R.L. (1993). A factor analytic study of language learning strategy use: Interpretations from information-processing theory and social psychology. Modern Language Journal, 7, 11-22.

Oxford, R.L. (1989). Use of language learning strategies: A synthesis of studies with implications for strategy training. System, 17, 235-247.

Oxford, R L (1990). Language learning strategies: What every teacher should know. New York: Newbury House.

O’Malley, J Michael \& Anna Uhl Chamot (1990). Learning strategies in second language acquisition. Cambridge: Cambridge University Press.

O'Malley, J. M., and Chamot, A. U. (1990). Learning strategies in language acquisition. New York: Cambridge University Press.

Politzer, R. (1983). An exploratory study of self-reported language learning behaviors and their relation to achievement. "Studies in Second Language Acquisition," 6, pp54-68.

Politzer, R., \& McGroarty, M. (1985). An exploratory study of learning behaviors and their relationship to gains in linguistic and communicative competence. TESOL Quarterly Profesor Badaruddin Mohamed, USM, Institut Penyelidikan Pendidikan Tinggi Negara (IPPTN), Oktober 2009, Kajian Pelajar Antarabangsa di Malaysia (jadual 1.2, pg 6) 19, 103--124.

Rubin, J. (1987). Learner strategies: Theoretical assumptions: Research history and typology. In A. Wenden and J. Rubin (Eds.), Learner strategies and language learning (pp. 15-29). Englewood Cliffs, NJ: Prentice Hall.

Rubin, J. (1975). What the "good language learner" can teach us. TESOL Quarterly, 9, 41-51.

Sherman, R.R., and Webb, R.B. (1990). Qualitative research in education: A focus, In R.R. Sherman and R.B. Webb (eds.) Qualitative research in education: Focus and methods, pp. 2-21. Philadelphia: The Falmer Press.

Skehan, P. (1989). "Individual differences in second language learning." London: Edward Arnold.

Tarone, E. (1983). Some thoughts on the notion of 'communication strategy'. In C. Faerch and G. Kasper (Eds.), Strategies in interlanguage communication (pp. 61-74). London: Longman.

Wharton, G. (2000). Language learning strategy use of bilingual foreign language learners in Singapore. Language Learning, 50(2), 203-244. 